\title{
Strategic and tactical risk in mining
}

\section{P.J. Bartlett South Africa}

\section{Abstract}

Mining is generally held to be a risky business. An understanding of the risks that impact on mining operations at all levels of risk including worldwide financial and commodity cycles, country risk, project risk and operational risks, all need to be considered and understood by mining operations irrespective of their size and complexity. To gain an insight into risk several definitions of risk are considered and an attempt is made to differentiate between strategic and tactical risks.

Strategic risks associated with mining are most commonly identified and considered during the exploration and the acquisition phases of mining operations and, in most of the major mining houses, are dealt with at the corporate level. Some strategic risks are briefly discussed. Country risk, considered by most mining companies as a strategic risk, is reviewed in some detail to illustrate how the perception of risk can have a major impact on the decisions of mining companies as well as on the economies of countries that are perceived to be risky. The potential impact of risks on mining projects is discussed.

Risks at an operational level on mines are reviewed to determine which of these can be considered strategic and which tactical. Ways in which risk is assessed and used to plan and operate mines is considered.

\section{Introduction}

One of the key issues that distinguish modern societies from pre-modern societies is how people conceive risk. Pre-modern cultures could not model risk in a systematic way because they lacked complex mathematics and a means of accurately measuring time. They fatalistically viewed life as something shaped by capricious gods or natural elements. Modern societies measure risk methodically and develop proactive strategies in response. We generally believe that risk can always be measured and contained. More recently "black swan" events, defined as "unexpected events of large magnitude and consequence that have a dominant role in history', have been recognised. Such events, considered extreme outliers, that collectively play vastly larger roles than regular occurrences, have become so numerous recently that we are coming to realise that we cannot always master risk.

\section{1 Discussion of strategic and tactical risk issues}

- Generally risk may be defined as the probability or threat of damage, injury, liability, loss, or other negative occurrence, caused by external or internal vulnerabilities, and which may be neutralised through premeditated action.

- More simply risk can be defined as "effect of uncertainty on objectives." (From ISO 31000:2009).

The concept of risk has three elements:

- The perception that something could happen.

- The likelihood (probability) of something happening.

- The consequences if it does happen.

Risk perception may be conceived as primarily a cognitive activity involving the accurate appraisal of external and internal states. By contrast, risk tolerance is better conceptualised as a personality trait. Risk tolerance may be defined as the amount of risk that an individual is willing to accept in pursuit of some goal. Four types of risk tolerance can be defined: physical, social, ethical and financial (Hunter, 2002). These 
risk tolerances do not necessarily correlate. Someone who enjoys mountain climbing and hang gliding may have a very low investment risk tolerance.

\section{2 Strategic risks}

Every organisation or major part of a complex organisation occasionally has to make some momentous decisions - the sort of decisions that affect the entire destiny of the organisation for years into the future. These decisions are designed to address the really biggest and most important issues facing an organisation - issues so significant we might call them 'strategic elephants'. So our definition of strategic planning must have something about big decisions.

Such decisions are not simply about small adjustments to activity levels, but are the kind of decisions that may lead to a substantially different organisational structure, or major changes in the relationships among key stakeholders, competitive position, or strategic partners of the organisation. Sometimes the outside world forces such decisions on the organisation. Such forces may include major shifts in the market, big changes in government policy, and radical moves by competing organisations. Sometimes, it is something inside the organisation that demands a major reappraisal. Technological change driving new methods of carrying out its work, or weakening of its financial structure, or a change in the senior management of the organisation requiring a large re-organisation are examples of such internal forces.

\section{3 Tactical risks}

Tactical risk is difficult to define but when an attempt is made to distinguish between strategic and tactical the following connotations frequently apply: tactical is short-term and strategic is long-term, tactical is small and strategic is big, tactical is ad hoc and often hastily planned, strategic is high quality. The following definitions of tactical and strategic are useful: tactical is something you are willing to change to meet local conditions and strategic is something you won't change to meet local conditions.

\section{4 Attitudes towards risk}

The attitude of many companies including mining companies towards risk mirrors the attitude of individuals towards risk. Insurance is one of the areas where risk was first formulated, considered and quantified. Table 1 sets out some lifetime risks with which most of us are familiar.

Table 1 Examples of some lifetime risks

\begin{tabular}{|c|c|c|c|}
\hline Activity & $\begin{array}{l}\text { Lifetime } \\
\text { Odds }\end{array}$ & Activity & $\begin{array}{l}\text { Lifetime } \\
\text { Odds }\end{array}$ \\
\hline $\begin{array}{l}\text { Odds a first marriage survives without } \\
\text { separation or divorce for } 15 \text { years }\end{array}$ & 1.3:1 & Chance of dying from an assault & 1 in 16,421 \\
\hline Odds of getting away with murder & $2: 1$ & Odds of being murdered & $18,000: 1$ \\
\hline Chance of dying from heart disease & $1: 3$ & Chance of dying from a car accident & 1 in 18,585 \\
\hline $\begin{array}{l}\text { Odds of being the victim of serious } \\
\text { crime in your lifetime }\end{array}$ & $20: 1$ & $\begin{array}{l}\text { Chance of dying in an airplane } \\
\text { accident }\end{array}$ & 1 in 354,319 \\
\hline $\begin{array}{l}\text { Odds of being in a serious motor } \\
\text { vehicle accident }\end{array}$ & 1 in 81 & $\begin{array}{l}\text { Chance of dying in a terrorist attack } \\
\text { while visiting a foreign country }\end{array}$ & 1 in 650,000 \\
\hline $\begin{array}{l}\text { Odds of being on plane with a } \\
\text { drunken pilot }\end{array}$ & $117: 1$ & $\begin{array}{l}\text { Chance of contracting the human } \\
\text { version of mad cow disease }\end{array}$ & $\begin{array}{r}1 \text { in } \\
40,000,000\end{array}$ \\
\hline $\begin{array}{l}\text { Odds of being audited by the Internal } \\
\text { Revenue Risk (IRS) }\end{array}$ & $175: 1$ & Chance of dying from a shark attack & $\begin{array}{r}1 \text { in } \\
300,000,000\end{array}$ \\
\hline Odds of having your identity stolen & $200: 1$ & $\begin{array}{l}\text { Odds of being killed on a five mile } \\
\text { bus trip }\end{array}$ & $\begin{array}{r}1 \text { in } \\
500,000,000\end{array}$ \\
\hline
\end{tabular}


If we consider our attitudes towards these risks our perceptions generally are:

- We perceive the outcome as being inevitable: we all die. By analogy the mine exists in a country and we cannot change the location so we accept this reality and its consequences.

- We consider that the risk is worth the reward: marriage, murder. By analogy a mining opportunity might offer exceptionally high rates of return.

- We appreciate the risk and take precautions: we complete our tax forms carefully to avoid an IRS audit. We try to keep our identity documents in a safe place. By analogy the group or mine recognises the risk and obeys all the rules and regulations to mitigate risk.

- Risks are very low and many people ignore them: airplane accident, shark attack: by analogy the mine must consider low probability-high consequence events such as floods, mud rushes and air blasts and take sensible precautions often prescribed by legislation.

Table 2 sets out the perceived major risks in mining during 2009 and 2010 as defined in the 2010 Ernst \& Young business risk report "Business risks facing mining and metals: the top 10 business risks for mining and metals." Risks are broadly classified as strategic, tactical or comparative.

Table 2 Major risks in mining in 2010 and 2009

\begin{tabular}{lcl}
\hline $\mathbf{2 0 1 0}$ & $\mathbf{2 0 0 9}$ & Risk Ranking Nature \\
\hline Capital allocation & 17 & Strategic \\
Skills shortage & 6 & Strategic \\
Cost management & 1 & Operational (tactical) \\
Resource nationalism & 9 & Strategic \\
Maintaining a social licence to operate & 4 & Operational (tactical) \\
Infrastructure access & 7 & Strategic \\
Access to secure energy & 8 & Strategic \\
Access to capital & 3 & Strategic \\
Price and currency volatility & 11 & Strategic \\
Climate change concerns & & Comparative \\
\hline
\end{tabular}

Of the 10 major risks defined in 2010 in the Ernst \& Young Report the following should be noted:

- Seven risks are defined as strategic, two as tactical and one as comparative.

- Risk rankings have changed markedly between 2010 and 2009, which does not fit with the generally held definitions of strategic risk which is generally considered to be long term.

- Not a single one of the defined risks relates to actual mining and processing operations. Risks considered important by mining groups and individual mines that relate to resources, reservescovered by the Australasian Code for Reporting of Exploration Results, Mineral Resources and Ore Reserves (JORC Code) and South African Code for Reporting of Exploration Results, Mineral Resources and Mineral Reserves (SAMREC Code) - and geotechnical risks are not considered in the report.

Many of the risks defined by Ernst \& Young (2010) are perceived by many to relate to country risk. 


\section{$3 \quad$ Strategic risk case studies}

\section{1 Country risk}

Country risk is usually considered to be a strategic risk. Table 3 has been taken from the Fraser Institute 2010/2011 Annual Survey of Mining Companies.

Table 3 Country risk - 2010 ranking of countries (McMahon and Cervantes, 2011)

\begin{tabular}{|c|c|c|c|c|c|c|c|c|}
\hline & Economic & Political & Social & Permitting & Corruption & Currency & Tax & Points \\
\hline 1. Australia & 9 & 9 & 8 & 8 & 10 & 8 & 7 & 59 \\
\hline 2. Canada & 10 & 10 & 6 & 5 & 10 & 9 & 7 & 57 \\
\hline 3. USA & 10 & 9 & 4 & 3 & 10 & 8 & 7 & 51 \\
\hline 4. Chile & 9 & 8 & 7 & 7 & 8 & 7 & 4 & 50 \\
\hline 5. Mexico & 8 & 8 & 5 & 8 & 7 & 6 & 8 & 50 \\
\hline 6. Greece & 8 & 8 & 3 & 3 & 5 & 8 & 6 & 42 \\
\hline 7. Brazil & 6 & 7 & 6 & 5 & 4 & 5 & 6 & 40 \\
\hline 8. Ghana & 6 & 5 & 5 & 7 & 4 & 5 & 6 & 38 \\
\hline 9. Argentina & 6 & 6 & 6 & 6 & 4 & 5 & 5 & 35 \\
\hline 10. China & 8 & 2 & 4 & 5 & 2 & 9 & 5 & 35 \\
\hline 11. Namibia & 5 & 6 & 3 & 5 & 4 & 5 & 6 & 34 \\
\hline 12. Mongolia & 6 & 4 & 5 & 6 & 3 & 6 & 3 & 33 \\
\hline 13. Tanzania & 5 & 5 & 3 & 7 & 3 & 4 & 5 & 32 \\
\hline 14. Peru & 6 & 3 & 1 & 3 & 4 & 7 & 5 & 29 \\
\hline 15. India & 6 & 6 & 2 & 3 & 3 & 5 & 3 & 28 \\
\hline 16. South Africa & 3 & 3 & 1 & 5 & 2 & 8 & 2 & 24 \\
\hline 17. Zambia & 4 & 4 & 2 & 5 & 3 & 2 & 4 & 24 \\
\hline 18. Kazakhstan & 4 & 4 & 4 & 3 & 1 & 4 & 4 & 24 \\
\hline 19. PNG & 4 & 4 & 1 & 2 & 2 & 4 & 5 & 22 \\
\hline 20. Bolivia & 4 & 1 & 1 & 4 & 3 & 4 & 5 & 22 \\
\hline 21. Russia & 2 & 1 & 3 & 3 & 1 & 4 & 6 & 20 \\
\hline 22. Indonesia & 3 & 5 & 1 & 3 & 1 & 1 & 3 & 17 \\
\hline 23. D.R. Congo & 1 & 3 & 3 & 3 & 1 & 1 & 4 & 16 \\
\hline 24. Zimbabwe & 1 & 1 & 1 & 3 & 1 & 1 & 2 & 10 \\
\hline 25. Venezuela & 1 & 1 & 1 & 1 & 1 & 1 & 2 & 8 \\
\hline
\end{tabular}

In Table 3 country risk is considered in terms of seven parameters. The mostly wealthy countries that are considered to be very prospective lose points in terms of social and permitting constraints. Countries lower down the rankings lose points primarily as a result of corruption and social concerns. In terms of social considerations wealthy countries have social concerns around the impact of mining whereas in developing 
countries, social concerns generally involve the local population not sharing in the wealth that mining creates.

The consequences of a deterioration in country risk for a country such as South Africa is substantial. A McKinsey study found that SA's mining sector shrank in real (2005) rand terms from R 103 billion in 1993 to R 92 billion in 2009 (Business Times Reporter, 13 February 2011). Major problems involve security of tenure, threats of nationalisation, an antiquated infrastructure and the ever present spectre of neighbouring Zimbabwe. The only major new project announced at the 2011 Indaba conference in South Africa was a R 1.45 billion project near Hotazel in the Northern Cape by a local mining company.

During the same period China's mining sector grew by $19 \%$, Russia by $10 \%$ and Indonesia by $8 \%$. (Business Times Reporter, 13 February 2011). South Africa has moved down the table substantially in the last few years, costing the country billions of rands and hundreds of jobs.

\section{2 Project risk}

The numerous risks associated with projects, including mining projects are well known. Independent Project Analysis, a group that has compiled a database of more than 5,000 projects, including mining projects, looks at factors and processes that lead to successful projects and also assesses how many projects can be considered successful in terms of schedules, costs, safety and reaching design capacity. Their findings are briefly summarised in Figures 1 and 2. Figure 1 shows that slightly more than $50 \%$ of projects meet their budgets, less than $50 \%$ meet schedules, $25 \%$ meet both budgets and schedules, $14 \%$ meet specifications and beat schedules, $11 \%$ meet specifications and come in below budget, $8 \%$ meet specifications and beat budgets and schedules, $7 \%$ work as expected, and only $3 \%$ meet all safety requirements as well. Obviously major lessons need to be learnt if the risks associated with projects are to be avoided. Figure 2 addresses some risk areas and clearly shows that detailed identification of important aspects of the project during the conceptual stage as well as definition of the project during the prefeasibility study stage when alternatives are selected, are essential in ensuring a successful project. Good execution cannot compensate for a poorly defined project. Effectively up front planning reduces risk at pre-concept, concept, pre-feasibility and feasibility level stages.

\section{De Berss $\quad$ Few Projects Meet All Objectives: How Do the Top Performers Do It?}

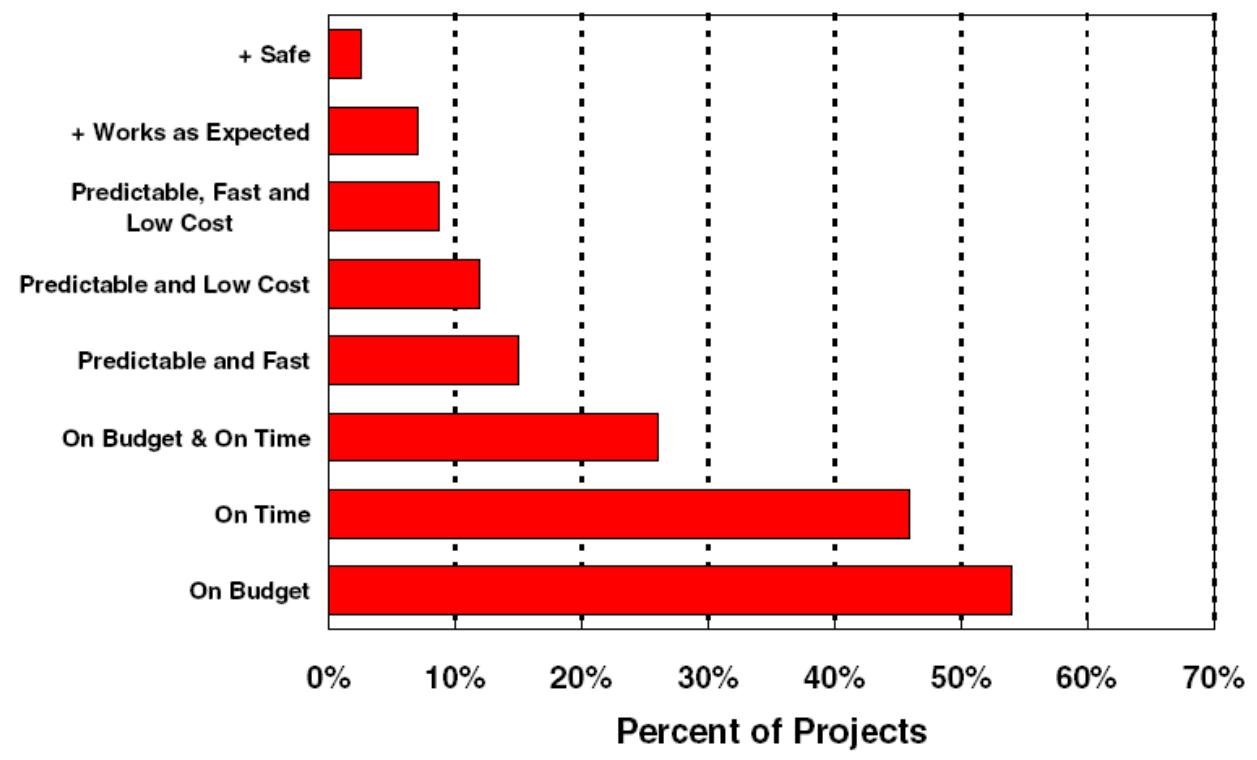

Figure 1 An assessment of project success (Independent Project Analysis Report, 2001) 


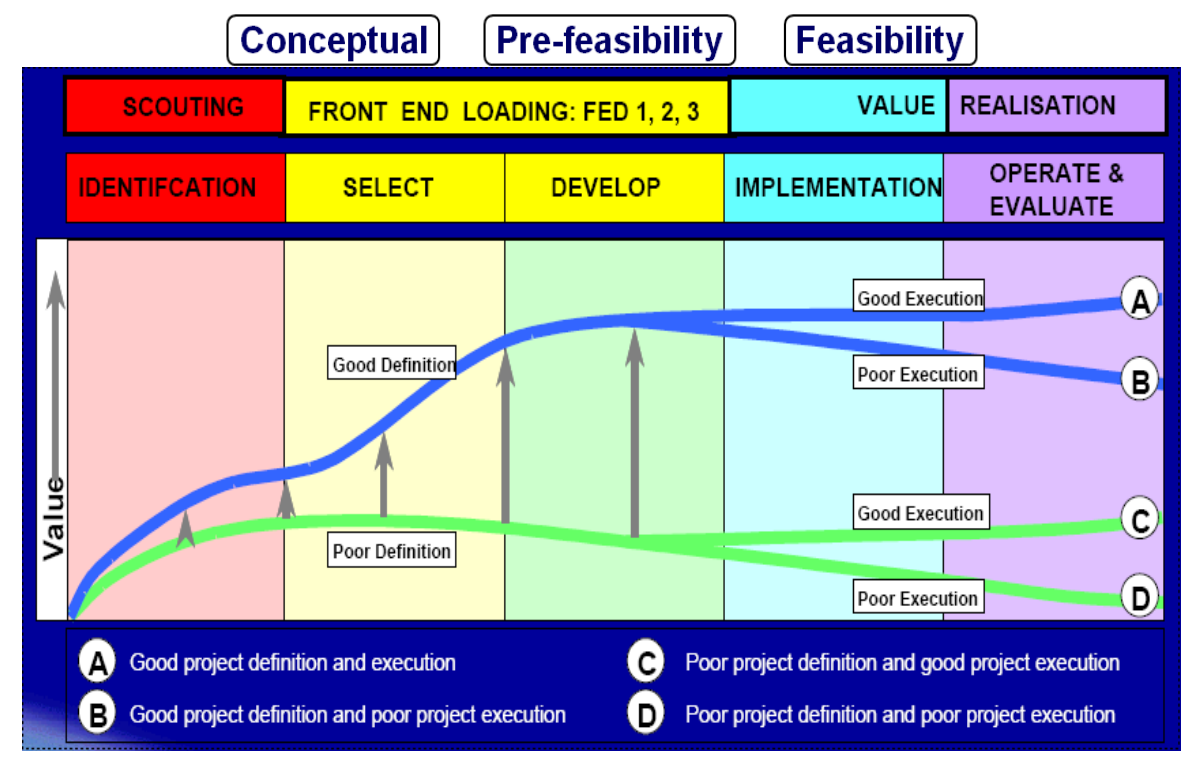

Figure 2 Project planning and execution (Independent Project Analysis Report, 2001)

\section{$4 \quad$ Tactical risk case studies}

\section{1 Hazard identification and risk management plan}

Many mining companies, often obliged to do so by legislation, have developed a risk management plan. Figure 3 sets out a typical process followed in developing and implementing the risk management plan. Risks are identified and assessed, where possible risks are then eliminated or mitigated. Typically risk assessments will be written to ensure that everyone, including newly trained employees, will have the same perception of risk in a particular situation. Safe work procedures are written, again to ensure that everyone is taught how to approach the task so that individual risk tolerance is minimised. The process is then monitored to ensure that the plan is effective.

\section{RISK MANAGEIMENT PROCESS}

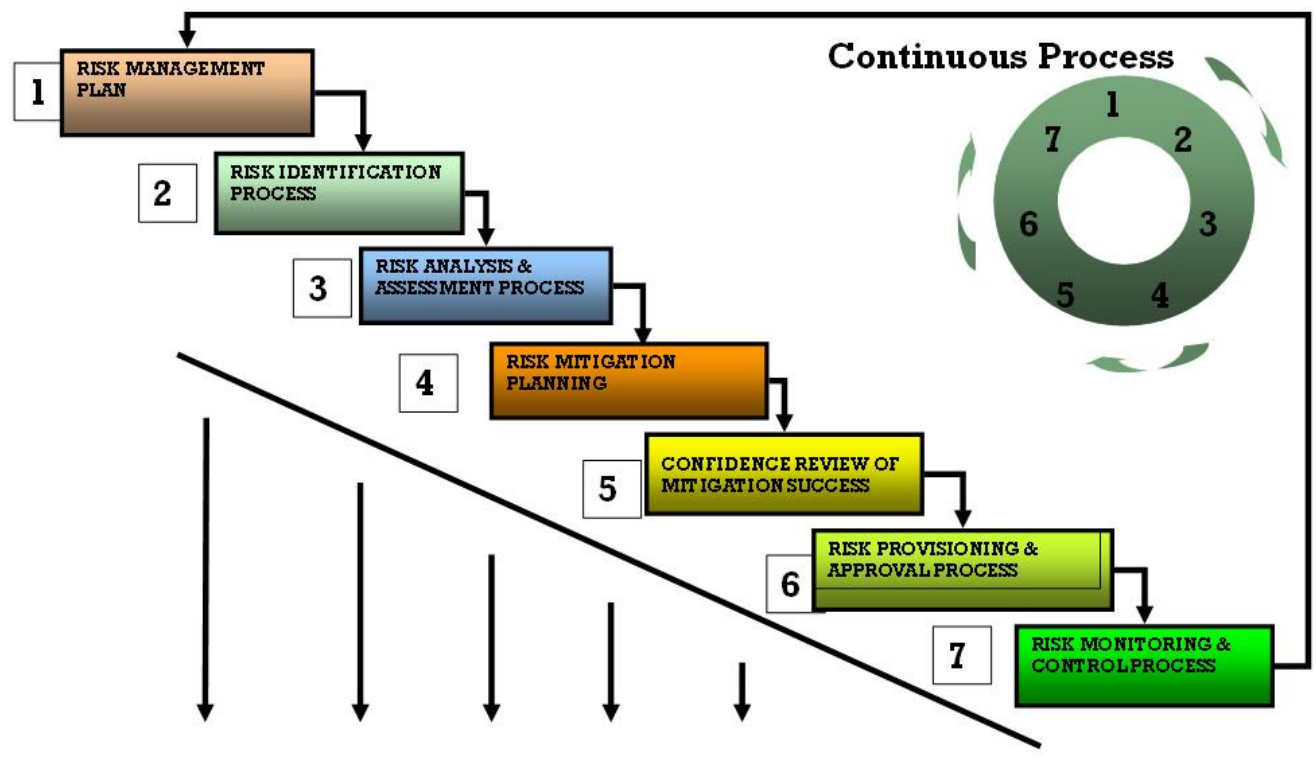

RISK DATA BASE

Figure 3 Risk management process 
Most operational aspects of mining can be incorporated into the risk assessment plan, including the probability that the resources and reserves of the mine will produce production results as planned. Geotechnical risk can be assessed and used to plan and anticipate the behaviour of large open pits. Figure 4 illustrates some of the major risks that can be identified during this process. Figure 4(a) shows the collapse of 130 million tons of pit sidewall at Palabora that has impacted on the exploitation of reserves as a result of early waste dilution. Figure 4(b) illustrates extensive subsidence at the Perseverance Mine in Western Australia. Figures 4(c) and (d) are of the Udachny open pit in Siberia where geotechnical risk has been correctly and advantageously assessed. The pit has produced 337 million t of ore and 380 million t of waste since mining started in 1967. The average stripping ratio is $1.12 \mathrm{t}$ of waste to $1 \mathrm{t}$ of ore. Pit walls are extremely steep with most benches $45 \mathrm{~m}$ high and with some benches as high as $105 \mathrm{~m}$. The safety factor for the pit sidewalls is calculated at 1.3 .
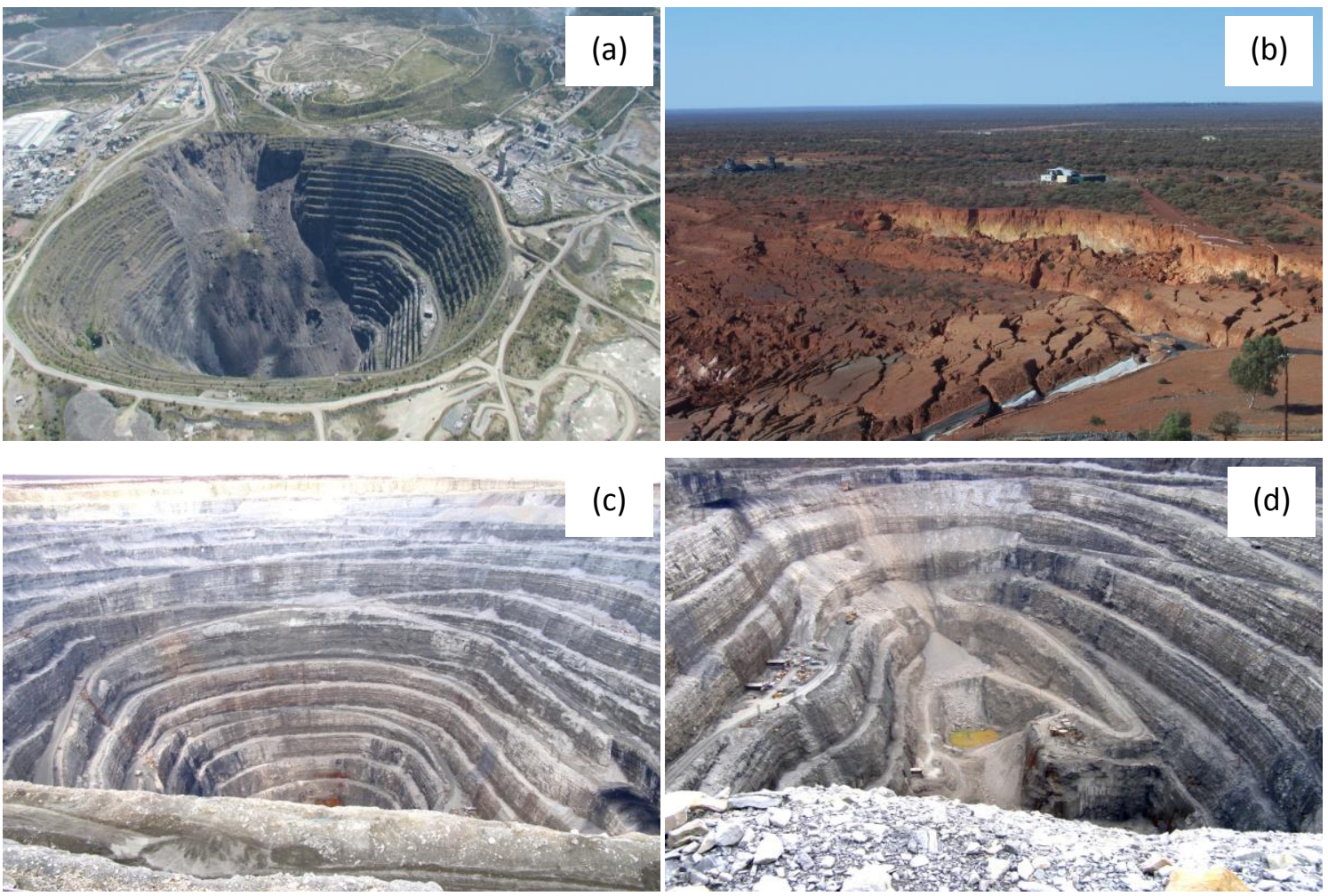

Figure 4 Photographs of (a) Palabora, (b) Perseverance and (c) and (d) Udachny open pits

More generally the risks defined and assessed in the iterative process set out in Figure 3 relate to operational issues such as construction, operating vehicles underground, mucking, drilling and blasting and tunnel development. The risks detailed in Figures 3 and 4 are typical risks that can be defined in assessing alternative mining methods at various stages of planning and implementation.

\subsubsection{Risk identification as a means of mining method selection}

Figure 5 illustrates a process where risk identification and assessment is used to assist in the choice of mining method at the pre-feasibility study stage.

Figure 6 illustrates a process whereby risks are identified and assessed during successive phases of project implementation. 


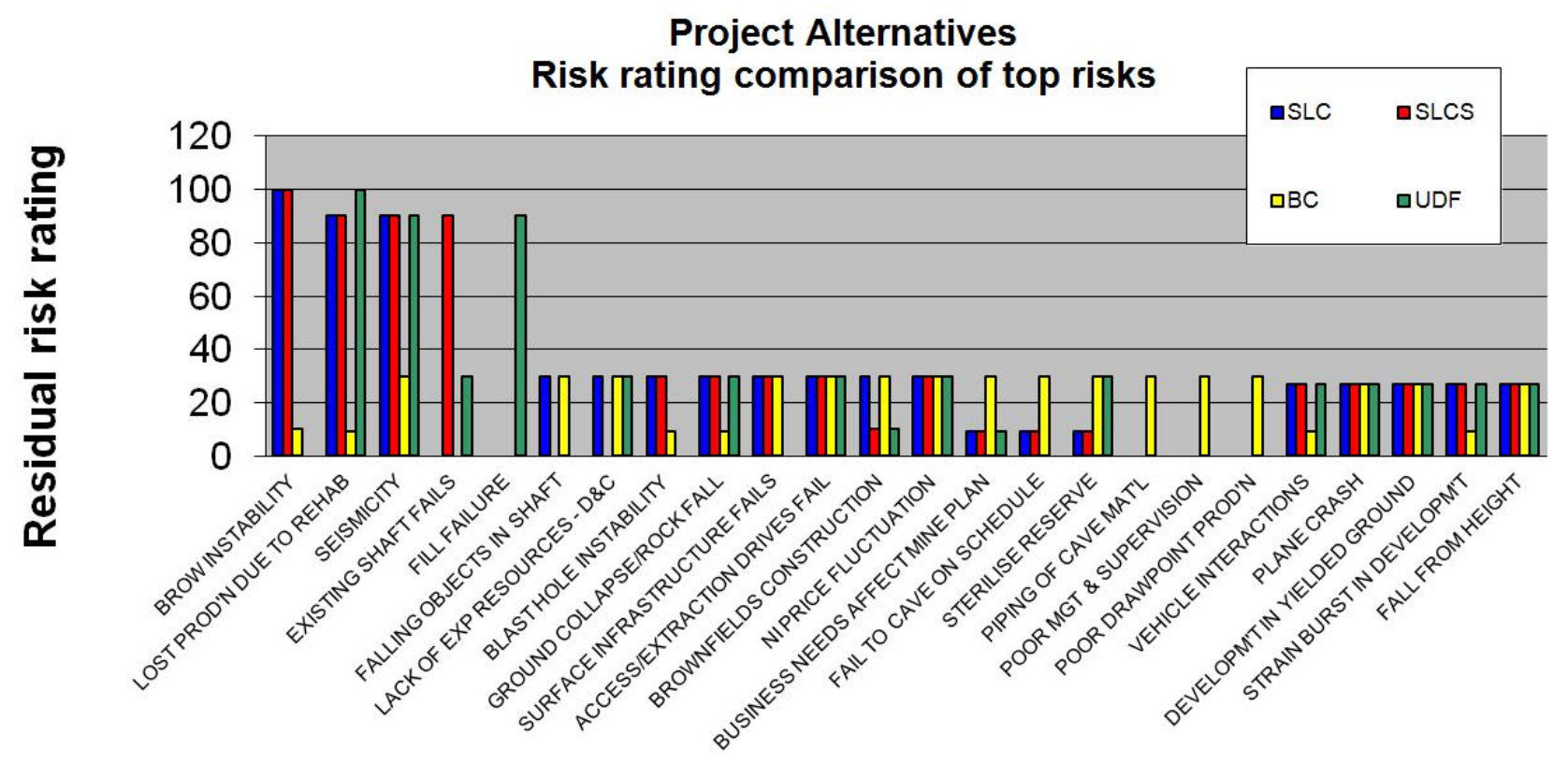

Figure 5 Risk identification used in choice of mining method

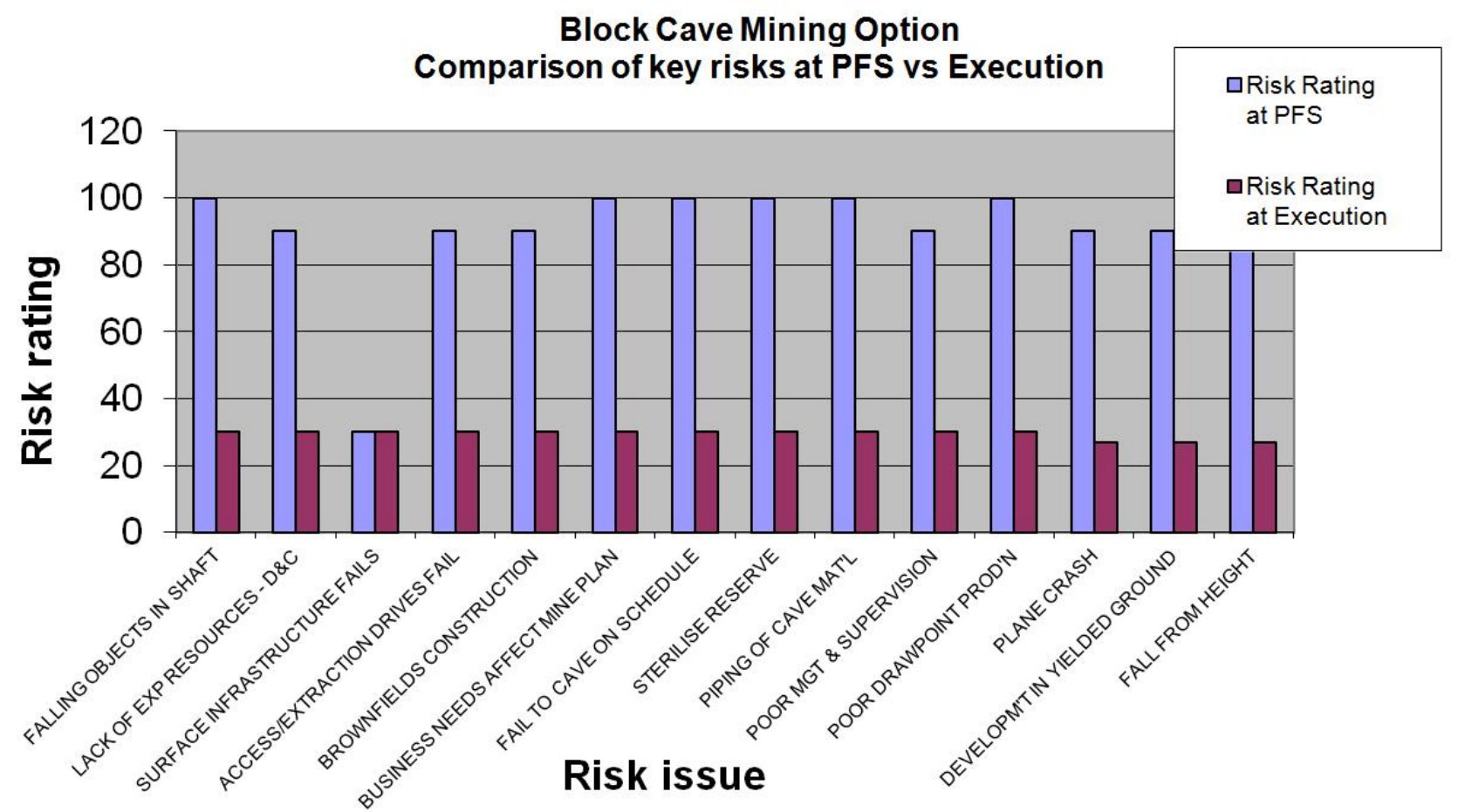

Figure 6 Risk assessment at various stages of a mining project

\section{Conclusions}

Risks associated with the mining industry form a continuum that range from what are obviously strategic risks in terms of most definitions to risks that are obviously tactical in terms of most definitions. Many risks will be judged as strategic or tactical depending on the company and the consequences of the risks for that mine or company.

Mining companies need to understand the risks associated with their mining operations to ensure that these are adequately addressed to ensure the safety of personnel and other production resources. 
A decision to mine in the wrong country or unsuccessfully implementing a major project can lead to the demise of a mining company.

A good risk management plan can pro-actively address risks and ensure that the company operates safely and cost effectively.

\section{References}

Business Times Reporter (13 February 2011) SA Will Miss Next Boom, viewed 15 February 2011, www.Timeslive.co.za.

Ernst \& Young (2010) Business risks facing mining and metals: the top 10 business risks for mining and metals, Business Risk Report. Hunter, D.R. (2002) Risk Perception and Risk Tolerance in Aircraft Pilots, Research and Special Projects Staff Federal Aviation Administration Office of Aerospace Medicine Washington, DC.

Independent Project Analysis Report (2001) Internal Report for C-Cut presented by IPA, Cullinan Mine, South Africa, Internal report. McMahon, F. and Cervantes, M. (2011) 2010/2011 Annual Survey of Mining Companies, The Fraser Institute, Vancouver. 
